\title{
Collaborating at the
}

\section{Centers}

REPORT FROM A STEM EDUCATION TRANSFORMATION

WORKSHOP INVOLVING LEADERS OF CENTERS FOR TEACHING AND

LEARNING AND STEM EDUCATION CENTERS

CASSANDRA HORII, KACY REDD, MATHEW OUELLETT, NOAH FINKELSTEIN, ANDREA BEACH, DEBORAH CARLISLE, SUSAN SHADLE, AND GABRIELA WEAVER
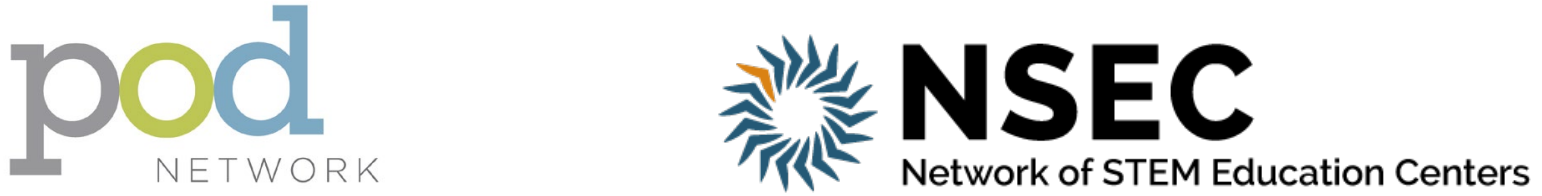


\section{TABLE OF CONTENTS}

TABLE OF CONTENTS 1

INTRODUCTION 2

KEY INSIGHT: UNDERSTANDING COMPLEMENTARY STRENGTHS 4

KEY INSIGHT: STRUCTURES AND NETWORKS 6

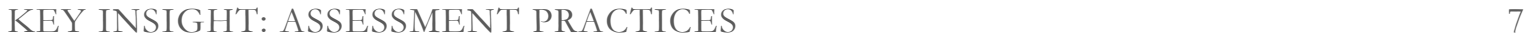

GUIDE TO COLLABORATING $\quad 8$

Starting Collaborations

Collaboration Process

Promising Forms of Collaboration

RECOMMENDED ACTIONS

10

For Centers and Institutions

For Networks of Centers

For National Organizations

CONCLUSION

REFERENCES

13

APPENDIX 1: WORKSHOP PROCESS

Workshop Charge, Participants, Agenda

APPENDIX 2: PRE-WORKSHOP WORK

Pre-Workshop Survey Questions

Pre-Workshop Survey Analysis

What Do We Know about Centers for Teaching and Learning and

STEM Education Centers?

Types of Faculty Support

Challenges of Centers

Collaborating Effectively with Centers

APPENDIX 3: PROMISING PRACTICES

Reform Pedagogy, Valuing Faculty, Scaling, Collaboration (to sustain new practices)

Institutional Support: Tools /analysis institutional data

APPENDIX 4: CENTERS' ROLE IN AND USE OF ASSESSMENT PRACTICES 34

APPENDIX 5: POST-WORKSHOP ACTIVITIES

Post-workshop Survey Results

Dissemination and Continuation of Collaborating at the Centers 


\section{INTRODUCTION}

The "Collaborating at the Centers" workshop brought together 46 invited participants and organizers from two distinct types of higher education centers, which are emerging as important campus contributors to national undergraduate science, technology, engineering, and mathematics (STEM) education improvement efforts: Centers for Teaching and Learning (CTLs), and STEM Education Centers (SECs).

CTLs have a history of over 50 years, representing the growth of faculty development, or more broadly educational development, efforts in the United States (Ortquist-Ahrens 2016). CTLs often work across disciplines, either institution-wide or within a school or college, supporting and advancing instructional practice, assessment, educational technology, professional development, and related areas for faculty, teaching assistants, and others. Many CTLs count as their main professional society the POD Network in Higher Education (POD, 2016), which has existed since 1976.

One of the first SECs emerged in 1959, but SECs have rapidly expanded since 2009. ${ }^{1}$ STEM education centers are hubs of campus-based efforts leading transformation of undergraduate STEM education, development and support of STEM teacher preparation, and engagement in the community and Broader Impact at their institutions (NSEC - Campus Centers, 2016; Riordan, 2014). Only recently has a network of such centers formed - the Network of STEM Education Centers (NSEC, 2016), supported by the National Science Foundation (\#1524832) and the Association of Public and Land-grant Universities (APLU).

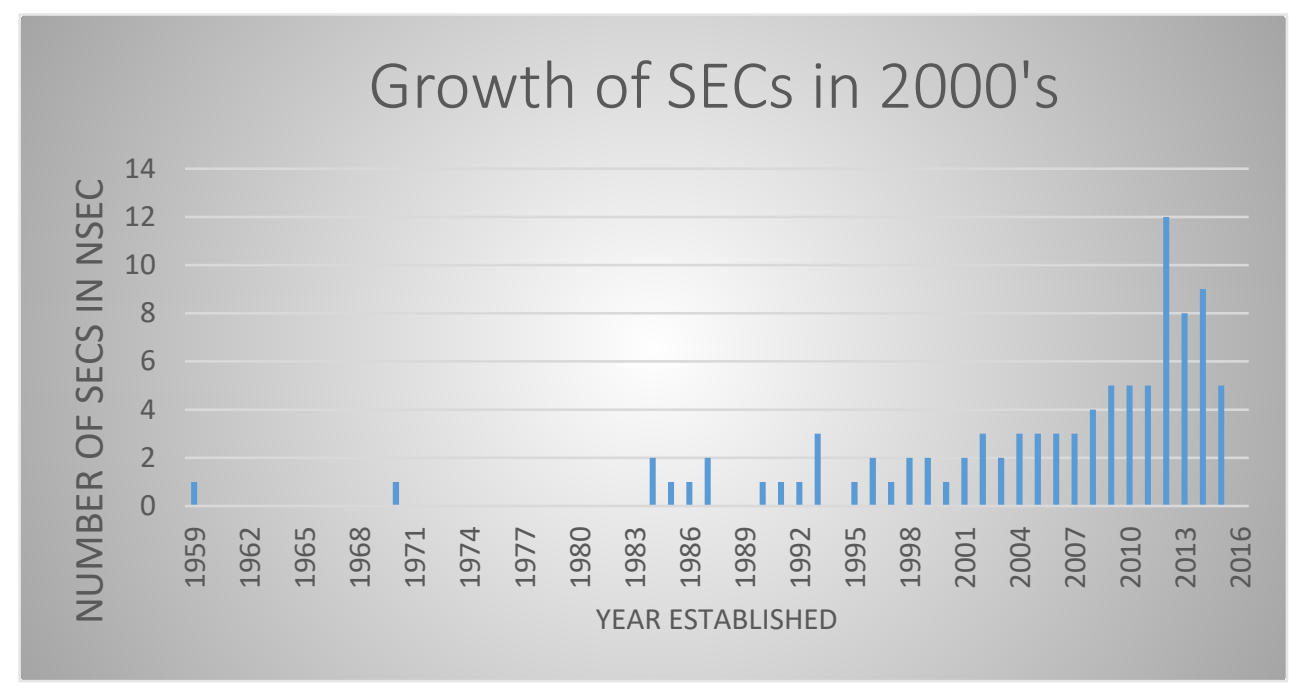

\footnotetext{
${ }^{1}$ Data is from 93 centers that have completed profiles at NSEC. It does not capture all SECs that currently exist or that have been established but no longer exist.
} 
Together, the POD Network and NSEC received funding from NSF (\#1552540) to convene the workshop following the 2015 POD Network conference on November 8, 2015, near San Francisco, CA. The goal of the workshop was to introduce these communities and discuss areas of synergy.

Prior to the workshop, participants completed a pre-workshop survey, which served as a foundation for shaping the workshop content. During the workshop, participants discussed and developed recommendations about the workshop themes:

- Commonalities and differences in the two center types' visions, goals, challenges, and mechanisms for leveraging change in undergraduate STEM education.

- Successful practices, ideas, and resources for prompting, leveraging, and sustaining change in undergraduate STEM education.

- Analysis of key gaps within and across the two networks working on STEM education.

- New strategies to act synergistically within and between campuses to provoke institutional change supporting STEM education improvement.

In addition to pre-workshop survey data, participants took collaborative notes in shared Google Drive documents, structured according to working sessions; for the small group discussions, these were organized by tables of approximately 10 people each. When assembled, the collaborative notes yielded over 550 distinct statements, each consisting of one or more sentences representing a complete thought. In addition, a separate set of notes about assessment were recorded. Statements were coded according to type of contribution (recommendation, question, promising practice, resource, challenge, context, gap, reference) and theme (collaboration, communication, structure and networks, leadership, people, sustaining change), with some statements addressing multiple types and themes. This rich dataset-from pre-workshop data to coded workshop notes and assessment notes-provides the basis for this report.

Below is an overview of key insights from the workshop, a guide to centers (CTLs and SECs) for productive collaboration on STEM education reform, and other recommended actions. Details about the workshop, pre-workshop data, workshop data analysis, promising practices repository, assessment details, and post-workshop analysis follow in a series of appendices. 


\section{KEY INSIGHTS: UNDERSTANDING COMPLEMENTARY STRENGTHS}

1. Centers, which are variable across and within center type (SEC and CTL), have shared strengths along with differentiated areas of expertise. Their distinct and complementary areas of expertise are potentially underutilized.

2. Articulating and sharing these strengths is important for building stronger collaborations.

\section{Complementary expertise is a potential untapped resource}

Overall, participants indicated that they were less familiar with one another's missions and strengths than they thought optimal. 140 out of 565 statements made during workshop discussions (25\%) addressed aspects relevant to center strengths, differences, and contexts. While there is a significant amount of variation within each group (not all CTLs are the same, nor are all SECs), some general trends emerged to help clarify how the two types of organizations are similar and unique. Often, these strengths were characterized as resources, as yet underutilized and representing existing human and intellectual capital to bring to bear on the challenges of educational change in STEM.

As this recognition of complementary strengths appears not to be well known across POD and NSEC, and is an important foundation for synergistic work and collaboration, it represents a key outcome from the workshop. An overview of complementary strengths may also help campus leaders and funding agencies better understand the roles that CTLs and SECs play in improving undergraduate STEM education. Given the areas of expertise catalogued below, it is worthy to note that both centers identified tension between defining their roles as responsive organizations (those prepared to act on opportunities to improve STEM education as they arise), versus visionary organizations (those setting the agenda and leading change, through strategy and implementation).

\section{SECs and CTL Shared Expertise}

- Pedagogical expertise. CTLs' expertise is more general and can span across disciplines, though is often well informed about STEM-specific evidence-based practices. SECs tend to have deep knowledge of STEM pedagogy informed by DBER (Discipline Based Educational Research).

- A connection to student success efforts on campus. Generally, SECs are connected more directly to students than CTLs. Both CTLs and SECs have experience working with identified groups of STEM faculty on issues of student learning and persistence in STEM.

- Involvement in institutional culture change. Both CTLs and SECs have experience working across departments/units of an institution to impact organizational change (catalyzing important discussions); building interdisciplinary networks by bringing individuals and units together for different purposes. For SECs, institutional change efforts are focused on STEM education reform. For CTLs, such efforts may be STEM-specific or may be more general across disciplines.

- Shared commitment to scholarly approaches. CTLs and SECs are informed by literature, and centers work collaboratively across unit boundaries to address teaching and learning challenges/institutional needs. 


\section{Complementary Strengths of CTLs and SECs}

\begin{tabular}{|l}
\hline \multicolumn{1}{|c}{ CTL Expertise } \\
\hline - Act from outside the department to \\
facilitate change. \\
- Experience with providing individual \\
instructor-level support and engaging \\
faculty about how to teach well (through \\
observation, consultations, student \\
feedback collection); experience applying \\
knowledge of pedagogy to workshop \\
design for faculty. \\
Deep knowledge of how to teach well; of
\end{tabular}
evidence-based practice informed by theory and research; of how to implement teaching methods in multiple disciplines (including formative assessment, pedagogical strategies).

- Experience bringing faculty cohorts together in learning communities; making connections between faculty and across disciplines; bringing multiple disciplinary perspectives together; focusing on reflective practice.

- Experience building trust and providing safe spaces (for individual faculty and for institutional change efforts); confidentiality practices in place when working with faculty.

- Knowledge of institutional systems; ability to act as hub to connect faculty and other units with each other.

- Deep knowledge of educational and faculty development literature; strong connections to national and global networks of educational development experts.

\section{SEC Expertise}

- Act within the department to facilitate change.

- Pedagogical content knowledge (PCK) - deep knowledge of teaching expertise in the STEM disciplines; knowledge of STEM-specific learning (e.g., misconceptions and threshold concepts).

- Deep knowledge of STEM disciplinary language and norms; credibility with STEM departments/faculty; experience with connecting across STEM disciplines.

- Experience with assessment and evaluation (summative and formative) of effectiveness of programs (serve as "evaluator" of instructor effectiveness for grant-funded and/or internal projects); support for STEM education research/connections to grants.

- Experience with teaching "pathways" (from K12 outreach, K-12 professional development, pathways into the teaching profession).

- Direct connections to STEM departments and undergraduate students - with knowledge of the support they need.

- Knowledge of programs, practices, and pathways that lead to student success in STEM.

- Connections to external stakeholders (public, governmental institutions, and business and industry).

- Expertise in science and quantitative literacy, public and community engagement, experience with systems thinking about the STEM pipeline and pathways

- Deep knowledge of Discipline Based Education Research (DBER) literature; strong connections to DBER faculty and their work, often homes for DBER scholars. 


\section{KEY INSIGHTS: STRUCTURE AND NETWORKS}

1. Mapping the space and understanding the context in which collaboration is to occur is an important lever of change.

2. Existing networks are an asset.

3. Leadership warrants special consideration.

Substantial discussions during the workshop focused on institutional and multi-institutional / network structures (e.g., organizational structures, reporting structures, institutionalized locations, and means of interacting), encompassing 203 of 565 statements $(36 \%)$.

\section{Mapping the space}

Mapping out any particular institution's structures and networks, including connections to faculty (within and across departments), students, funders, and community partners, appears to be a strong approach to setting up successful collaborations and sustaining STEM educational change. These networks can be thought of in terms of funding, staffing, and other structures. For example, an SEC may have access to certain types of funding, such as grants for STEM transformation, or be able to more easily hire research or postdoctoral fellows to assist with projects. SEC leadership and staff (who are often faculty, too) may have greater access to STEM faculty. By working with an SEC on campus, a CTL may increase its opportunities for involvement or enhance existing opportunities to build relationships with STEM faculty. A CTL may be able to tap into long-standing networks of faculty allies on campus, as well as conferences or institutes beyond the institution, to help advance the work. When these unique structural characteristics and networks are brought to bear on the challenge of STEM educational reform, the results could be more effective than otherwise possible.

\section{Using existing networks}

Building on one area of complementary strength articulated above, workshop discussions identified strategic and intentional use of the different but overlapping networks of CTLs and SECs in STEM educational change: e.g., institutionalizing change at the STEM department level (an approach that

SECs have found helpful), while tapping into cross-disciplinary STEM interest and communities for support and learning (an area of CTL expertise, particularly in facilitating faculty learning communities).

\section{Importance of leadership}

Reporting structures and institutional leadership warrant special consideration, particularly as reporting structures for SECs and CTLs may differ substantially. Participants emphasized the importance of advocacy from campus leaders both within formal reporting structures and beyond them, as well as using alignment with espoused leadership objectives to seek internal funding to start and/or sustain efforts. Building multiple channels of support among campus leaders, and keeping them well informed, is also vital when specific personalities leave the institution. 
1. Center mission impacts assessment practices.

2. Centers help translate assessment into action that leads to improved educational outcomes.

\section{Center mission impacts assessment practices}

Assessment practices were identified as a "growth area" for both CTLs and SECs and were a special focus for a portion of the workshop. Often, centers view themselves as facilitators and thus use assessment in collaboration with departments and faculty. Centers were involved in two types of assessment: 1) assessing the impact of their own programs, 2) partnering with faculty and/or departments to assess curricular innovations. Our main workshop insights focus on the latter.

Centers with more involvement assessing the impacts of STEM education reform efforts, often but not always SECs, tended to identify themselves more strongly as catalysts for change. Differences in mission, for example the fact that SECs are frequently involved in DBER research that requires data to demonstrate outcomes, was an important contributor to this distinction between centers. CTLs' historical role and emphasis on formative and confidential work with faculty in some cases precluded greater involvement in formal assessment efforts, as summative assessment work could potentially make them less neutral or detract from their reputations as safe places for faculty to collaborate, experiment, and work toward improved teaching practices. However, some CTLs are playing a growing role in departmental and institutional assessment of learning. Both CTLs and SECs strive to use current and progressive assessment tools and methods to inform the continuous improvement of teaching and learning.

The collective network of SECs and CTLs identified a variety of assessment tools and approaches with potentially powerful insights, from holistic and psychosocial measures (e.g., identity, selfefficacy, motivation) to student outcomes and pathways (especially data visualization tools and approaches), to exit surveys and pre-post measures. See Appendix 4 for further discussion.

Centers identified several challenges to the use of effective assessment practices:

- the need to align data collection with institutional priorities,

- $\quad$ the need to identify course and program level outcomes, and

- the lack of consistency between assessment done by faculty, which confounds data aggregation.

\section{Centers help translate assessment into action}

The shared challenge in using any assessment approach involves engaging faculty and stakeholders in the resulting insights in order to advance change objectives and sustain the work. The complementary areas of strength across SECs and CTLs may be particularly relevant for addressing this key challenge in assessing STEM educational impacts. 


\section{GUIDE TO COLLABORATING}

In her workshop keynote speech, "The Roles of STEM Education Centers and Interdisciplinary Teaching and Learning Centers in Transformative Change in STEM Undergraduate Education: What Questions Should We Consider?," Dr. Ann Austin, Program Director of the Division of Undergraduate Education at the National Science Foundation, identified important movements since the 1980s toward faculty development that is learner-centered and backed by evidence, and the importance of networks in sustainable organizational change and research-based practice in higher education. In this "age of the network," achieving transformative change in STEM education requires effective and informed collaboration across units within institutions, as well as nationally.

Workshop participants devoted a substantial amount of time to developing a guide to effective CTLSEC collaborations. Overall, participants emphasized, through a variety of perspectives, a collective impact model: that is, to approach cross-unit collaborations by inviting everyone to the table, creating relevant leadership groups, and keeping stakeholders informed. In the long and challenging strategic process of improving undergraduate STEM education, this foundation should inform future actions. The following points of guidance summarize participants' extensive insights on this topic.

\section{STARTING COLLABORATIONS}

In addition to externalizing and articulating goals (a common practice among CTLs and SECs for any project or work) to locate specific shared areas and differences ("points of connectivity and points of divergence"), participants suggested having an informal memorandum of understanding $(\mathrm{MOU})$, ground rules, or a shared framework for collaborating. These up-front discussions and agreements allow for clear articulation of challenges and priorities, real or perceived competition (i.e., knowing where resources are coming from for each center, so care is taken not to jeopardize resource streams through collaboration), and even "hands off' areas for different centers. One group identified this cluster of themes as mapping the "territory of collaboration," which might include identifying common elements of mission as well as differentiated strategies, strengths, stakeholders, expertise, resources, and benefits from participating in shared projects. Ownership of data and protocols for sharing and publishing are also helpful to discuss in the planning stages of collaborations.

Aside from the logistical details, articulating the centers' individual and collective working metaphors or models of action can help clarify effective ways of working together and any potential differences in culture or methods. Participants identified potential models and metaphors to consider: hub, bridge, boundary spanner, Venn diagram, emergent third space, concentric circles (e.g., identifying fraction of focus on undergraduate STEM education for each center), grassroots, top down, etc. 
Building on complementary strengths articulated above, beginning collaborations should also identify roles and their synergistic functions early on. This step helps centers with articulating their purpose and involvement to leaders higher in their reporting structures (why they are needed, their expertise), as well as what they gain by participating (e.g., access to different faculty or groups that help further their distinct mission). For example, SEC staff may function as subject experts in STEM on projects that CTLs are hosting, such as faculty learning communities; CTL staff may function as process experts to facilitate educational development with faculty or others on projects that SECs are advancing.

Finally, new or emerging SEC/CTL collaborations may be sensitive to special challenges. For example, early stages of information sharing about activities may feel like a "slap in the face" if perceived as encroaching on another group's mission or domain if they happen before an MOU or framework is in place; one solution is to share information in conjunction with the open invitation to contribute or participate.

When inviting another center to collaborate, acknowledging stretched staffing and resources can be accomplished by articulating different possible modes of collaborating at various levels of commitment (e.g., consult, co-create) and normalizing different responses as helpful and not damaging to the centers' relationship (e.g., thank you for letting us know and good luck, we don't have the bandwidth to contribute right now but would like to stay informed, we are able to consult, we would like to collaborate).

Timing and the stakes of the project should also be considered when reaching out to other centers. In general, the higher the bar (e.g., for external funding), the more advance notice and planning time are needed.

\section{COLLABORATION PROCESS}

Workshop participants brought discernment to the details of processes and mechanisms in multicenter STEM education collaborations. The importance of multiple forms of person-to-person interaction across collaborating centers was a recurring theme. While center leaders need to communicate, staff and other collaborators also need mechanisms for doing so. For example, "play dates," brown-bag seminars, or "dine and discuss" events can bring people from different groups or centers together in an open-ended way to explore areas of shared interest and strengthen the foundation of relationships that foster collaboration. These kinds of connections fill in for the "water cooler" effect for groups that do not share space.

Participants also recommended starting collaborations with small projects to build rapport and collaborative methods before moving on to larger projects, such as major grant proposals, for which 
funders are also likely to value a history of collaboration and success. Recording progress and making success visible is crucial in this process; in other words, be sure to celebrate early wins. Also consider how collaborations are co-branded and credited, with diplomacy around marketing and communications.

\section{PROMISING FORMS OF COLLABORATION}

The following specific ideas emerged as ones with strong potential, and in some cases established success, for involving both SECs and CTLs in improving undergraduate STEM education:

- New faculty training/institutes

Collaborate to help faculty establish effective teaching practices early in their careers.

\section{- STEM education postdocs}

Collaborate to provide mentoring in complementary areas of strength.

\section{- Seminars or colloquia}

Collaborate to organize a shared series on STEM education to explore research and practices applicable in a local context.

\section{- Liaisons}

Collaborate on day-to-day support for STEM instructors, such as liaison roles between the SEC, CTL, instructional technology office, etc. Build capacity for centers to be "concierges" for additional support by knowing other offices' functions and expertise well enough to refer.

\section{- Course/curriculum (re)design}

Collaborate to work closely with faculty and departments when small or large changes are being considered and planned.

\section{- Students}

Collaborate to gather and build on student perspectives to leverage STEM education change. Collaborate to involve students as participants in STEM education change (e.g., as learning assistants).

\section{- Research}

Collaborate to summarize research relevant to STEM education. Collaborate to conduct new research on STEM education.

\section{- Learning spaces}

Collaborate around the needs assessment, design, implementation, and assessment of new types of learning spaces for STEM.

\section{- Adjunct faculty}

Collaborate on ways to involve part-time and non-tenure track faculty teaching undergraduate STEM without overburdening them.

\section{- Future faculty}

Collaborate on preparing and mentoring next generation STEM faculty in effective and inclusive STEM education practices.

\section{- Institutional change}

Collaborate to strengthen interdisciplinary work and work that moves beyond the walls of the university, and incubate new ideas and approaches with seed funding. 


\section{RECOMMENDED ACTIONS}

Beyond the institutional level, workshop participants had the following broader recommendations for advancing shared work on undergraduate STEM education.

\section{FOR CENTERS AND INSTITUTIONS}

- Employ and share assessment tools and practices to assist in closing gaps and supporting the use of high impact practices.
- Develop assessment tools to provide information on which areas to address and tailor to department and faculty needs.

\section{FOR NETWORKS OF CENTERS}

- Expand the summary of types of centers/units and their respective strengths in contributing to STEM educational change: e.g. Institutional Research, Writing Centers, Student Success Centers, Disability Resource Centers, Diversity Centers, Cocurricular Centers, Institutional Review Boards, STEM Teacher Preparation and Professional Development Centers, Higher Education Research Centers/Departments.

- Design a sponsored workshop that brings together SEC/CTL teams to plan and carry out collaborative work.
- Strengthen mechanisms and structures for multi-institution collaboration.

- Create more opportunities for workshops with broad and open participation process.

- Set standards and create toolkits for practice for new centers (CTLs, SECs, and others) that include understanding of other units on campus with whom they may collaborate, and guidance on how best to collaborate.

- Share conference announcements and calls for proposals across national networks.

\section{FOR NATIONAL ORGANIZATIONS}

- Incorporate STEM-specific cases and collaborations in the Organizational Development and Leadership Institutes sponsored by the POD Network.

- Cultivate continued conference sessions that expand networks across CTLs, SECs, and other units around STEM educational reform.

- Plan a special journal issue or feature about STEM educational reform from the perspective of SECs and CTLs.
- Bring challenges and barriers to national professional organizations such as institutional consortia, so they may help gather information and make recommendations to Provosts and Presidents (e.g., AAU, AAC\&U, APLU).

- Create special/topical interest groups around STEM within professional organizations to sustain and include new colleagues in collaborative work. 


\section{CONCLUSION}

Building on Dr. Austin's remarks, participants suggested that the "age of the network" may be giving way to the "age of implementation"- that is, an era during which our collective networks must become adept at working together to effect real and sustained change in undergraduate STEM education. We must join our strengths strategically, work together to identify the levers of change, and address gaps where we are not yet able to effect or sustain change. Although the work of collaboration on implementation — at institutional, multi-institutional, and national levels - may be "messy," workshop participants pointed out that it is "productively messy" work, and very much worth doing.

Such collaborations could be a powerful force in advancing the goal of improving undergraduate STEM education. They may also yield insights about the process that can help sustain and accelerate STEM transformation, and broader educational improvement efforts at colleges and universities. Workshop participants' called for new research to answer vital questions about the role of students as allies and change agents; time and effort needed to adopt and sustain new STEM educational practices; faculty affect, motivation, and barriers; and the ways in which new types of assessment data are used.

Finally, the workshop participants and organizers alike recognize that CTLs and SECs represent only a fraction of the potential and necessary collaborators involved in STEM educational change efforts and that even these categories are by no means clear-cut in many cases. We hope that some of the key insights, points of guidance on collaboration, and recommendations may spark additional insights and be relevant despite the necessary limitations of any organizational framework 


\section{REFERENCES}

Network of STEM Education Centers. (n.d.). Retrieved May 20, 2016, from

http://serc.carleton.edu/StemEdCenters/index.html

NSEC - Campus Centers. (n.d.). Retrieved May 20, 2016, from

http://serc.carleton.edu/StemEdCenters/campus_centers.html

Ortquist-Ahrens, L. (2016). Beyond Survival: Educational Development and the Maturing of the POD Network. To Improve the Academy, 35: 1-34. doi: 10.1002/tia2.20031

POD Network. (n.d.). Retrieved May 20, 2016, from http://podnetwork.org/

Riordan, D.G. (2014). STEM education centers: a national discussion. APLU/SMTI Paper 8.

Washington, DC: Association of Public and Land-grant Universities. Available at http://www.aplu.org/projects-and-initiatives/stem-education/SMTI Library/stem-educationcenters-report/file 


\section{COLLABORATING AT THE CENTERS}

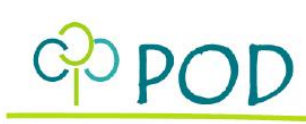

Professional and Organizational Development Network in Higher Education

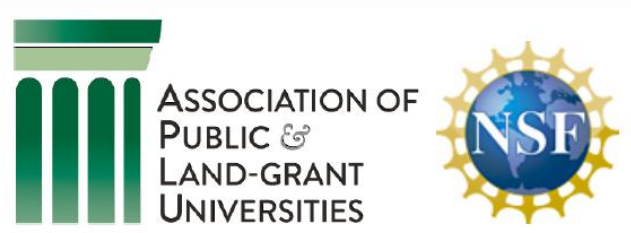

Co-hosted by the POD Network in Higher Education and the APLU STEM Center Network

Following the 2015 POD Network in Higher Education Conference

\section{A WORKSHOP ON STEM TRANSFORMATION}

\section{Purpose}

This workshpp brings together directors and senior leaders of STEM Education Centers and of interdisciplinary Teaching and Learning Centers. To date, these groups have worked on meaningful but often parallel initiatives on improving undergraduate STEM teaching and learning. By coming together, these communities of practice will extend networks, better understand each other's visions and goals, and explore how working together can enhance each other's efforts on campus, across institutions, and nationally.

\section{Structure}

The workshop will be highly active, with a few short, focused talks to broaden our perspectives and a series of working sessions structured to tap into our diverse expertise and make real progress on our mutual STEM education goals.

\section{Schedule}

\section{Sunday, November 8:}

11:00-2:00 pm

Opening and Lunch

2:00-6:00 pm

Working Sessions: Break-outs and Re-convenings

6:00-8:00 pm

Dinner \& Synthesis Discussions

\section{Monday, November 9:}

8:00 - 10:00 am

Breakfast and Wrap-up

\section{Outcomes}

Participants will contribute to developing, and leave with a greater understanding of:

- Commonalities and differences in different types of centers' visions, goals, challenges, and mechanisms to leverage change in undergraduate STEM education.

- Successful practices, ideas, and resources for prompting, leveraging, and sustaining change.

- Analysis of key gaps within and across our networks of centers working on STEM education.

- New strategies to act synergistically within and between campuses to provoke institutional change supporting undergraduate STEM educational improvement. 


\section{WORKSHOP PARTICIPANTS}

The 46 workshop participants came from 32 US higher education institutions and four national professional organizations. Participants were invited based on combined lists from the POD Network's informal STEM interest groups and the APLU's list of STEM Education Centers, with an emphasis on inviting as many institutions serving underrepresented minorities and other underserved students as possible. Some institutions with both SECs and CTLs sent participants from both centers, or from other similar units on campus. There was no registration fee and all workshop meals were provided, along with up to two nights lodging at the conference hotel; participants or their institutions funded their own travel and any other costs associated with attending.

The institutional participants represented 22 public and 10 private not-for-profit colleges and universities. By Carnegie Classification, they included 26 Doctoral Universities (20 Highest Research Activity, four Higher Research Activity, and two Moderate Research Activity), four Master's College and Universities Doctoral Universities (two Small Programs, two Medium Programs), and two Baccalaureate Colleges: Arts and Sciences Focus. While additional Hispanic Serving Institutions (HSIs) and Historically Black Colleges and Universities (HBCUs) were invited, only one HBCU and two HSIs were represented, along with one institution with a focus on serving low-income students.

Prior to the workshop, participants received a pre-workshop survey that asked about their center's programmatic activities, biggest challenges to their center, if and how they worked collaboratively with other centers and what those advantages and challenges were. For the full list of questions, see Appendix 2. These responses were used to help refine the agenda. Workshop organizers provided the analysis of these responses to the attendees prior to the workshop on November 2, 2015.

A few days prior to the workshop on November 2, 2015, participants received an email asking them to consider a few questions that would be discussed in small groups at the workshop. These are included in the Agenda below. 


\section{Sunday, November 8 - Bayside Room, Lobby Level}

11:00 - 12:15 Workshop Charge and Introductions

Keynote by Dr. Ann Austin, Program Director Division of

Undergraduate Education, National Science Foundation

12:15 - 12:45 Lunch (buffet)

12:45 - 2:00 Centers for Teaching \& Learning (CTLs) and STEM Education Centers (SECs):

Pre-workshop Data, Challenges, and Expertise

Lightning Rounds and Facilitated Discussions

Questions to guide discussion

- What expertise do Centers for Teaching and Learning (CTLs) bring to address STEM education challenges? What expertise do STEM

Education Centers (SECs) bring to address STEM education challenges?

- How do these two communities of expertise complement each other?

2:00-2:15 Break

2:15 - 4:00 Promising Practices

Lightning Rounds and Facilitated Discussions

Questions to guide discussion

Faculty Engagement

- What are some of your best practices around engaging faculty? This is not limited to STEM faculty.

\section{Institutional Support}

- Has your institution adopted any benchmarks or targets with respect to their goals and vision for the improvement of undergraduate STEM education? What are they?

- Have you found effective ways of gaining administrator buy-in? Assessment and Evidence

- What types of assessment, both formal and informal, is your Center currently using to gain information on undergraduate STEM 
students' experience at your institution? Student experience includes factors related to learning and persistence, as well as engagement, retention, paths in STEM, overall performance, etc.

- Are there additional types of evidence you would like to gather to help inform the kinds of programs offered by your Center?

- What forms of evidence do you collect to measure the impact of your programs on undergraduate STEM education? (E.g. grant funding, improved retention rates, faculty engagement, data on improved student performance in redesigned courses, etc.).

- If you have any assessment methods that have been particularly successful, please share those.

- Can you share an example of a way in which gathering data on programs has helped you to meet your goals?

4:00-4:15 Break

4:15 - 6:15 Drafting a guide to Collaborating at the Centers for STEM Transformation

Questions to guide discussion

- What are some strategies and best practices for building effective collaborations either collaborating within a campus; or between campuses/within networks?

- What is needed to deepen and facilitate the collaborative relationships between Centers for Teaching and Learning and STEM Education Centers?

Identification of Interest Clusters for Dinner Discussions

6:15 - 7:30 Dinner, Discussion, and Insights from the Day

\section{Monday, November 9 - Bayside Room, Lobby Level}

7:30 - 8:00 Breakfast

8:00 - 10:00 Mapping Next Steps:

Research, Networks, National Organizations, Campus-level Actions 


\section{APPENDIX 2: PRE-WORKSHOP WORK}

\section{PRE-WORKSHOP SURVEY QUESTIONS}

Thank you for participating in "Collaborating at the Centers: A Workshop on STEM Transformation" for directors of STEM Education Centers and interdisciplinary Teaching and Learning Centers following the POD Network in Higher Education Conference, November 8-9, 2015, at the San Francisco Hyatt Regency Airport Hotel. Please fill out this survey to help inform the workshop plans. It will take approximately 10 to 15 minutes. Many thanks and we look forward to seeing you in November!

\section{Part 1: Confirmation of RSVP Information}

1. Below is the information you provided in your RSVP. If you have any updates or corrections, please write them in the space provided.

Name:

Email:

Title:

Center or Unit:

Institution or Organization:

Type of Center:

\section{Part 2: Centers and Collaboration}

2. Please answer the following questions from the perspective of your organizational role within or overseeing center(s) or unit(s) involved in STEM education reforms.

3. In your center or unit: What is the administrative title of lead person? To whom does the lead person report?

4. How central to your center or unit's mission is excellence in undergraduate STEM education? Choose (Not central; Somewhat central; Central; Its sole mission)

5. To what extent is your center or unit involved in the types of projects or programs listed below, for the improvement of undergraduate STEM instruction? The projects or programs do not need to be exclusively STEM-focused, but should involve STEM in some way. Choose (Not involved; Becoming involved soon; Occasionally involved; Regularly involved; Frequently involved)

- Research on STEM educational effectiveness

- Training for new STEM faculty (first year, including postdoctoral fellows)

- Training for new STEM teaching assistants, tutors, or other non-faculty instructors

- On-going professional development for STEM faculty

- On-going professional development for STEM teaching assistants, tutors, or other nonfaculty instructors

- STEM curricular initiatives 
- Projects specific to underrepresented groups in STEM

- Other:

6. What types of faculty support related to the improvement of undergraduate STEM courses does your center or unit offer? Please check all that apply. As above, these types of faculty support need not be exclusively STEM focused, but should be available to STEM faculty.

- Assistance with the adoption of evidence-based practices and/or student-centered pedagogies in STEM

- Course design for in-person STEM courses

- Course design and/or development for online STEM courses

- Instructional technology applications and/or support for STEM faculty

- Best practices for teaching diverse students in STEM

- Teaching as research or scholarship in STEM, including experimental design and data collection

- Implementation of evidence-based, disciplinary educational practices in STEM

- Mentoring undergraduate STEM research experiences

- Curriculum mapping across multiple STEM courses

- Learning outcomes assessment in STEM

- Other:

7. What are the main programmatic activities or practices from your center or unit that you would want others to know about--the "promising practices" in use for STEM educational improvement that you would be willing to share?

8. What is the biggest challenge your center or unit faces in supporting improvement of undergraduate STEM education?

9. Are there programmatic activities that you would like to learn more about during the workshop?

10. Does your campus have (or is your campus planning to start) a center or unit other than yours, which contributes to undergraduate STEM education efforts? Please do not list academic STEM departments that house STEM faculty and courses; rather, focus on other centers or units with administrative, supportive, and resource-providing functions.

- $\quad$ Yes (if so, please name other center(s) or unit(s):

- $\quad$ No

11. I am not affiliated with a college or university campus

12. How important is it to work collaboratively with the center(s) or unit(s) named above? Please define collaboration broadly, such that collaborative work may include jointly planning and implementing programs, sharing expertise and ideas, communicating with one another regularly, supporting one another's initiatives through dissemination, and similar actions. Choose (Not important; Somewhat important; Important; Very important)

13. In what specific ways is your center or unit collaborating effectively with the center(s) or unit(s) named above? 
14. What problem(s) might the center(s) or unit(s) named above help you solve?

15. What challenges do you face in working collaboratively with the center(s) or unit(s) named above? For example, are there organizational barriers, cultural differences, discrepancies in language or jargon, other pressures, different priorities, internal or external challenges, distinct reporting lines, funding differences, etc.?

16. As a solo center or unit working on STEM education improvements at your institution, are there ways in which collaborating or exchanging information with center(s) or unit(s) at other institutions might help you solve problems or overcome challenges you face at your campus?

17. As someone working from outside a specific college or university, please share your perspective on collaboration and information exchange between different types of centers and units contributing to undergraduate STEM education improvement, and on collaboration and information exchange between colleges and universities.

\section{Part 3: Concluding Thoughts}

18. Prior to receiving the invitation to Collaborating at the Centers: A Workshop on STEM Transformation, please rate your awareness and involvement with the POD Network in Higher Education and the STEM Education Centers Network: Choose: Very Low; Low; Medium; High; Very High)

- Awareness of the POD Network in Higher Education

- Awareness of the STEM Education Centers Network

- Involvement with the POD Network in Higher Education

- Involvement with the STEM Education Centers Network

19. Please list key professional organization memberships and conferences that support your work with STEM Education Reform.

20. Is there anything else you would like to share with the workshop organizers to help inform planning of the workshop? As a reminder, the workshop's intended outcomes are for participants to contribute to developing, and leave with a greater understanding of: commonalities and differences in different types of centers' visions, goals, challenges, and mechanisms to leverage change in undergraduate STEM education; successful practices, ideas, and resources for prompting, leveraging, and sustaining change; analysis of key gaps within and across our networks of centers working on STEM education; and new strategies to act synergistically within and between campuses to provoke institutional change supporting undergraduate STEM educational improvement. 
PRE-WORKSHOP SURVEY ANALYSIS

WHAT DO WE KNOW ABOUT THE PARTICIPANTS?

38 participants responded to the pre-workshop survey, including 13 (34\%) STEM Education Centers (SECs), 17 (45\%) Centers for Teaching and Learning (CTLs), 5 (13\%) hybrid SEC/CTL or an oversight office for one or both, and $3(8 \%)$ other, such as national organizations. 20 participants held the title of Director, with a few titles such as Coordinator, Provost, Assistant Provost, Associate Provost, and Vice Provost $(n=25)$. The majority of the centers report to either a Provost (13) or Dean (10), with a smaller number reporting to the Chancellor (1), Vice president (2), or Executive director (4).

Sixty percent of responding centers $(n=20)$ reported that their institutions have or are planning to start a second kind of center, which would contribute to undergraduate STEM education efforts. The types of centers included:

- SECs or CTLs

- Other types of centers or units: offices of instructional technology and e-learning; assessment; undergraduate research; diversity; science literacy; research on evidencebased instruction; K-12 STEM education and lifelong learning.

WHAT DO WE KNOW ABOUT CENTERS FOR TEACHING AND LEARNING AND STEM EDUCATION CENTERS?

Excellence in undergraduate STEM education is more central to the mission of SECs than CTLs.

When asked to rate centrality to mission on a four-point scale (Not central $=1$, Somewhat central $=2$, Central $=3$, Its sole mission $=4$ ), the SEC Mean $=2.5$ and the CTL Mean $=2.0(p=0.05)$. Note that excellence in undergraduate STEM education is not the sole mission of many SECs. More commonly, it is somewhat central to SECs' missions.
How central to your center or unit's mission is excellence in undergraduate STEM education?

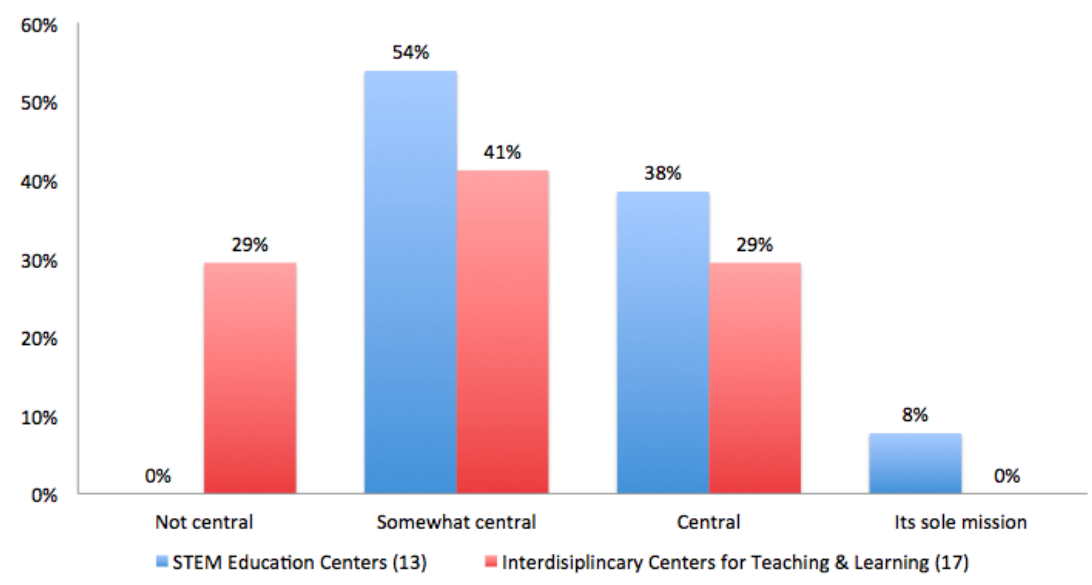


There are some differences in the involvement in projects and program types based on center type:

- CTLs in our sample report more involvement with faculty in STEM, both ongoing professional development and new faculty training.

- SECs report more involvement with underrepresentation, educational effectiveness research, and curricular initiatives in STEM.

- SECs and CTLs participate roughly equally in work with STEM Teaching Assistants (TAs), tutors, and non-faculty instructors.

- The five hybrid (both SEC and CTL) or overseeing offices look more like CTLs in some cases (work with faculty, research), and more like SECs in others (underrepresentation, curricular initiatives). Overall, they report more involvement with STEM TAs, tutors, and non-faculty instructors than SECs or CTLs.

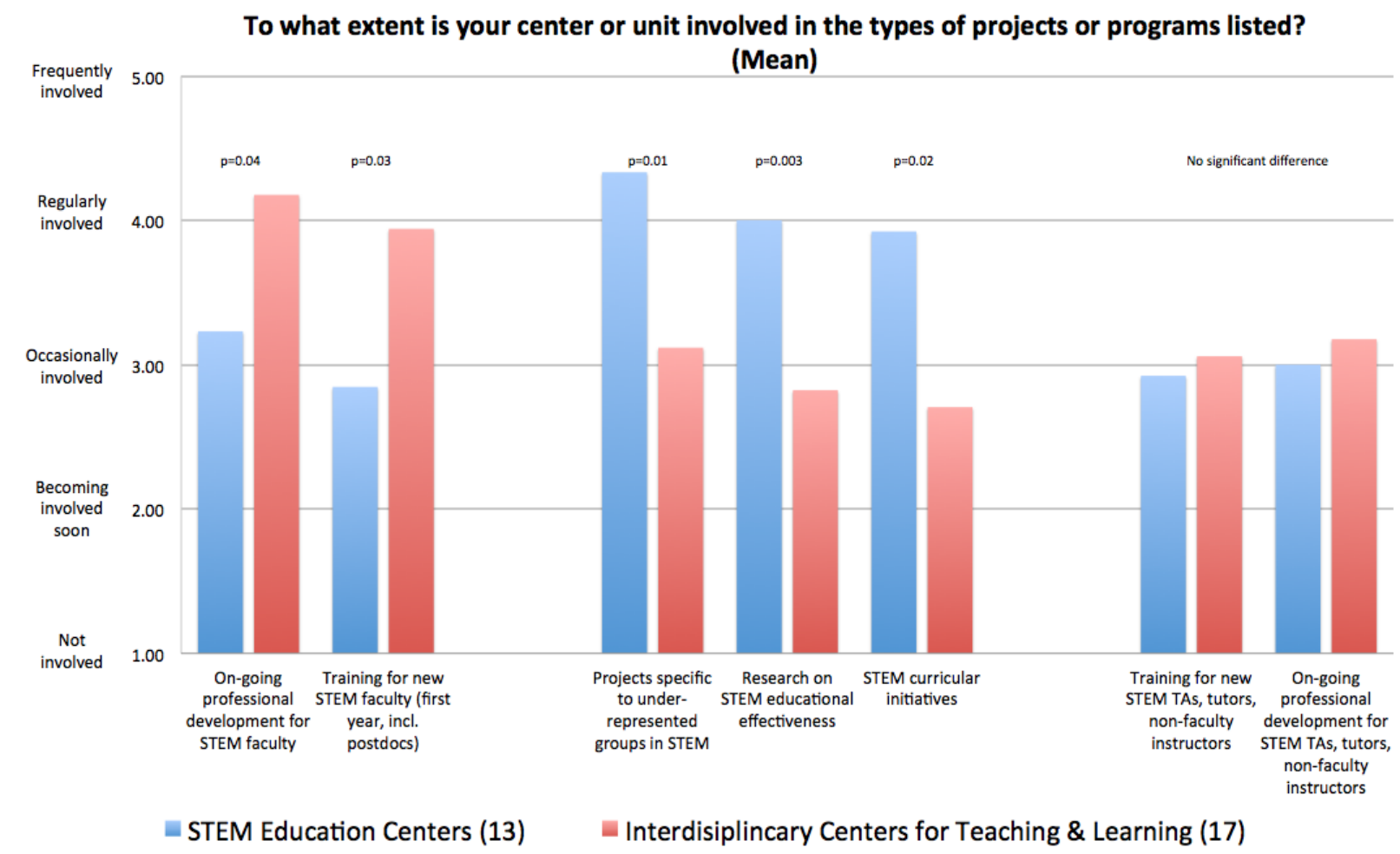

Other types of projects and programs reported include:

- Faculty learning communities (a form of professional development) and other community building efforts

- PK-12 teacher professional development \& STEM pipeline projects

- Broader impacts and other forms of grant-writing and development for STEM education

- Involvement in STEM education/transformation grants (e.g., WIDER, IUSE) 


\section{TYPES OF FACULTY SUPPORT}

We asked what types of faculty support related to the improvement of undergraduate STEM courses each center or unit offered. For most types of faculty support, SECs and CTLs offer them at similar rates (slightly higher for CTLs, consistent with their reportedly higher extent of involvement in ongoing professional development and training for STEM faculty above). ${ }^{*}$ Exceptions are noted below, where SECs and CTLs differed.

\section{MOST COMMONLY OFFERED: (percent of all centers)}

$\circ$ Adopting $\mathbf{( 8 6 \% )}$ and implementing $\mathbf{( 8 0} \mathbf{0})$ evidence-based practices \& student-centered pedagogies in STEM.

- Teaching as research/scholarship in STEM (74\%). * Stronger emphasis for SECs than CTLs. $\circ$ Learning outcomes assessment in STEM (71\%).

- Course design for in-person STEM courses; best practices for teaching diverse students in STEM. Each (69\%)

\section{LESS COMMONLY OFFERED: (percent of all centers)}

- Mentoring undergraduate STEM research experiences $(26 \%)$. ${ }^{*}$ Much stronger emphasis for SECs: only $6 \%$ of CTLs reported this form of support, compared to $54 \%$ of SECs.
- Curriculum mapping across multiple STEM courses $(\mathbf{4 0} \%)$.

- Course design/development for online STEM courses $(\mathbf{4 6} \%)$.

- Instructional technology for STEM faculty (49\%).

OTHER forms of faculty support:

- Development/assessment of education research proposals and training grant

- Student Identity in STEM.

- Assistance with curriculum/program design (not just course-level design).
- Connecting with other institutions and national initiatives (AAU, BayView etc.).

\section{CHALLENGES OF CENTERS}

Overall contrasts between SECs and CTLs:

- SECs note funding as a challenge more often than CTLs.

- CTLs note faculty buy-in more often (approximately twice as much) as SECs.

- CTLs note the need for more time to address needs related to STEM education. 


\begin{tabular}{|c|c|}
\hline \multicolumn{2}{|c|}{$\begin{array}{l}\text { What is the biggest challenge your center or unit faces in supporting improvement of } \\
\text { undergraduate education? What problem(s) might other center(s) or unit(s) help you solve? }\end{array}$} \\
\hline Themes & $\begin{array}{l}\text { STEM Education Centers (SECs) }(n=13) \\
\end{array}$ \\
\hline Funding & $\begin{array}{l}\text { - Funding is the largest obstacle. Research and professional } \\
\text { developments takes dollars, particularly with time-intensive activities. } \\
\text { - Funding for staff and resources to support ambitious curriculum } \\
\text { improvement and faculty development projects } \\
\text { - Sustained institutional funding, initially started w/extramural Funds } \\
\text { now temporarily supported internally } \\
\text { - Budget } \\
\text { CTLs or other centers might help with: funding justification and } \\
\text { institutional permanence. }\end{array}$ \\
\hline Scaling & $\begin{array}{l}\text { - Integrating many programs across campus; implementing best practice } \\
\text { as scale } \\
\text { - Working across all disciplines in STEM } \\
\text { - Capacity. Support for service to the university. } \\
\text { - Involved in teaching reform conversations and, even among "allies" } \\
\text { we struggle to find a common vision for models that involve ideas } \\
\text { such as transdisciplinary coursework, hiring plans involving DBR } \\
\text { focus, and offering graduate tracks with education focus in the } \\
\text { sciences. }\end{array}$ \\
\hline $\begin{array}{l}\text { Reform } \\
\text { Pedagogy }\end{array}$ & $\begin{array}{l}\text { - Implementing student centered pedagogies in large enrollment classes } \\
\text { - Supporting lecturers who have little time for PD } \\
\text { - Willingness of faculty to engage, and to move beyond a strict lecture } \\
\text { approach. } \\
\text { CTLs or other centers might help with how to improve teaching } \\
\text { and learning to increase workforce development; effective } \\
\text { infrastructure, practices, and policies; offering professional } \\
\text { development particularly for STEM faculty. }\end{array}$ \\
\hline Faculty Buy-in & $\begin{array}{l}\text { - Building adequate faculty and department buy-in and support. } \\
\text { - Supporting faculty resistant to reform teaching }\end{array}$ \\
\hline
\end{tabular}




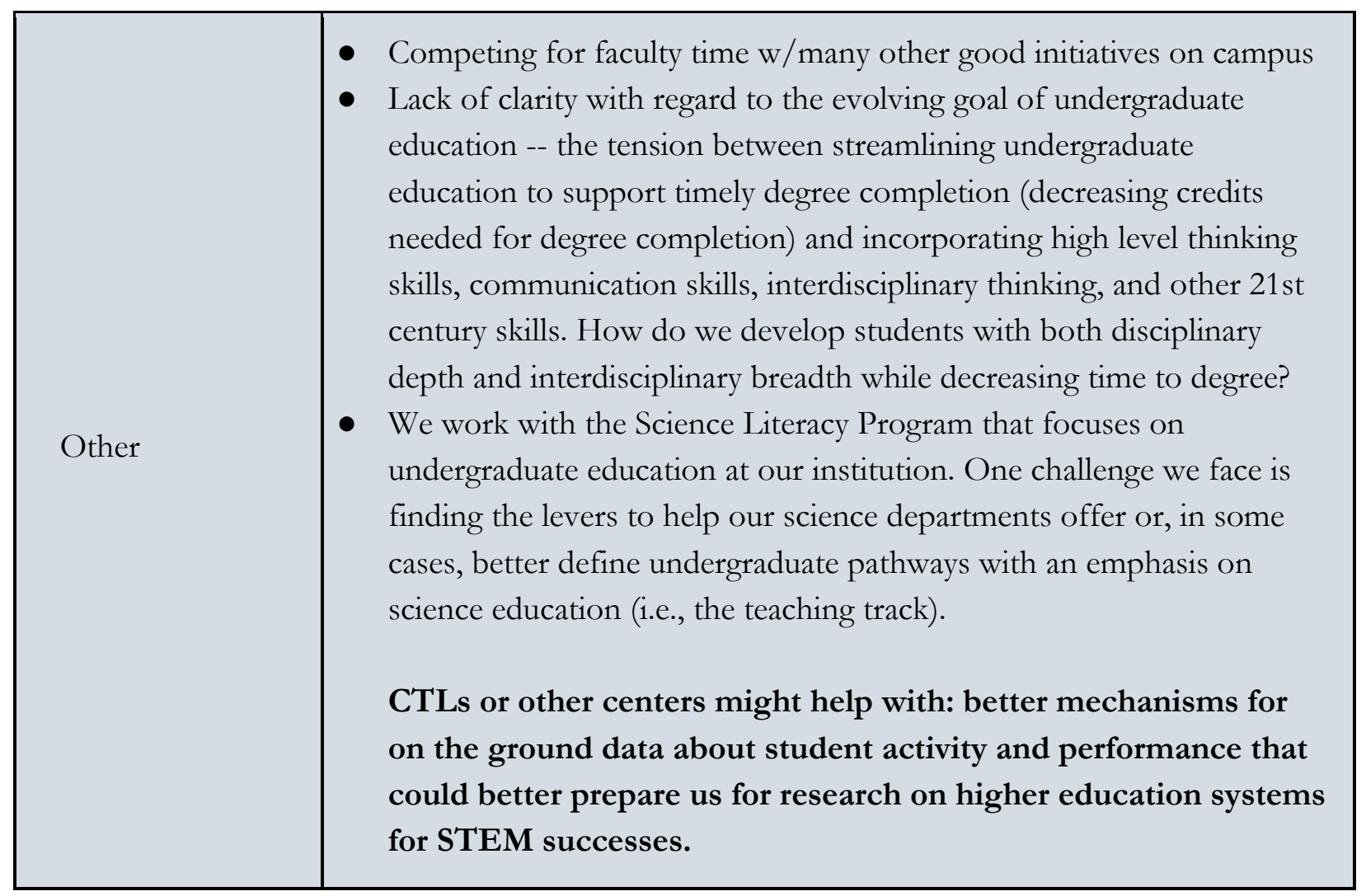

\begin{tabular}{|c|c|}
\hline Themes & Centers for Teaching and Learning (CTLs) $(n=17)$ \\
\hline Faculty buy-in & $\begin{array}{l}\text { - Shifting culture to get faculty to engage, } \\
\text { - Getting faculty to use our services; } \\
\text { - Faculty time constraints and pressure from the reward system. } \\
\text { - Resistance to new pedagogy, and learning platforms } \\
\text { - Quite a few STEM faculty on our campus are not yet persuaded that } \\
\text { learning pedagogies our Center promotes can be applied to their } \\
\text { (large) courses. } \\
\text { Willingness of faculty to engage, and to move beyond a strict lecture } \\
\text { approach. } \\
\text { SECs or other centers might help with: connecting with a wider } \\
\text { range of faculty (drawing on relationship with STEM faculty); } \\
\text { credibility; incentives; sustaining interactions with STEM } \\
\text { departments. }\end{array}$ \\
\hline
\end{tabular}




\begin{tabular}{|c|c|}
\hline $\begin{array}{l}\text { Reform } \\
\text { Pedagogy }\end{array}$ & $\begin{array}{l}\text { - Lack of emphasis on active learning; } \\
\text { - Scholarship focus with few structural incentives (P\&T) to encourage } \\
\text { pedagogical innovation. Department level cultures that discourage } \\
\text { active learning instruction among pre-tenure faculty. Lack of } \\
\text { institutional leadership for and explicit commitment to active } \\
\text { learning. } \\
\text { - The biggest challenge is willingness of faculty in the STEM } \\
\text { disciplines to consider changing their pedagogies in light of recent } \\
\text { evidence. Partly this is a result of time pressures and the rewards } \\
\text { structure, but it also involves a larger discussion of what constitutes } \\
\text { convincing evidence in a social science realm (i.e., education) for a } \\
\text { STEM audience that is used to a much more controlled environment } \\
\text { with more definitive findings. } \\
\text { Institutional value of teaching }\end{array}$ \\
\hline Time and Staff & $\begin{array}{l}\text { - Directors time (spread thin), } \\
\text { - Personnel to promote STEM change and focus on STEM } \\
\text { - As a research center, we are necessarily limited in the time we can } \\
\text { spend in hands-on curricular/pedagogical implementation. That is } \\
\text { not our mission. But, our university CTL does not have the } \\
\text { personnel to focus on STEM change initiatives. So, leveraging all of } \\
\text { the potential resources to make change on campus is our biggest } \\
\text { challenge. } \\
\text { SECs or other centers might help with: time/resource crunch } \\
\text { (facilitate connecting CTLs' general expertise and experience } \\
\text { with professional development approaches such as learning } \\
\text { communities) with STEM domain-specific language and } \\
\text { examples; bandwidth to amplify and extend CTLs' work. }\end{array}$ \\
\hline $\begin{array}{l}\text { Fragmentation/ } \\
\text { Priorities/ } \\
\text { Leadership }\end{array}$ & $\begin{array}{l}\text { - Silos } \\
\text { - Institutional valuing of instructors versus tenure track faculty } \\
\text { - Changes in key leadership roles } \\
\text { SECs or other centers might help with coordination of grant } \\
\text { proposals; continued and persistent communication. }\end{array}$ \\
\hline
\end{tabular}




\begin{tabular}{|l|l|}
\hline \multirow{1}{*}{ Competition } & $\begin{array}{l}\text { Concern from within our center (from staff) that we may be focusing } \\
\text { too much effort towards STEM, to the detriment of relationships } \\
\text { and support of faculty in other disciplines. Non-STEM faculty are } \\
\text { very sensitive to the fact that STEM gets lots of attention and } \\
\text { resources. Their sense that they get less and less of the pie (not just } \\
\text { in the CTL, but across campus) is not imagined and we have to be } \\
\text { sure we are serving the whole institution. } \\
\text { SECs or other centers might help with: Providing resources for } \\
\text { the improvement of STEM teaching. }\end{array}$ \\
\hline Workload & $\begin{array}{l}\text { STEM faculty on our campus carry a disproportionate student- } \\
\text { teacher ratio as compared to most other faculty. This leaves them } \\
\text { with little time, energy, and/or inclination to seek optional } \\
\text { professional development in teaching. }\end{array}$ \\
\hline Size & $\begin{array}{l}\text { I'm not sure it's the biggest challenge, but one of the challenges } \\
\text { we've faced in our work is being at a small PUI with no TAs, etc. } \\
\text { Adapting findings to our context is often difficult. }\end{array}$ \\
\hline
\end{tabular}

\begin{tabular}{|l|l|}
\hline Themes & \multicolumn{1}{c|}{ Centers with dual role (hybrids) or oversight offices (n=5) } \\
\hline & $\begin{array}{l}\text { - funding, structural changes in provost's / president's office } \\
\text { - currently focusing on rebranding Center \& developing partnerships } \\
\text { with departments that support our new mission }\end{array}$ \\
$\begin{array}{l}\text { Miscellaneous: } \\
\text { funding, } \\
\text { structure, } \\
\text { branding, } \\
\text { incentives, } \\
\text { change, } \\
\text { alignment }\end{array}$ & $\begin{array}{l}\text { STEM Ed are not aligned with those for retention, tenure and } \\
\text { promotion } \\
\text { pace of change, difficulty in faculty acceptance, student evaluation of } \\
\text { teaching } \\
\text { Working with higher levels of institutional leadership to align } \\
\text { fragmented efforts for more substantial change e.g., making sure that } \\
\text { when funds are awarded to faculty to improve undergraduate STEM } \\
\text { education, the results/outcomes are gathered and communicated to } \\
\text { others within and across STEM disciplines. We have pieces in place, } \\
\text { but often not linked together. }\end{array}$ \\
\hline
\end{tabular}




\section{COLLABORATING EFFECTIVELY WITH CENTERS}

When we asked centers with both CTLs and SEC on their campus how important is it to work collaboratively with the other center, $85 \%$ felt it was very important or important to work collaboratively $(n=20)$.

The survey asked in what specific ways is your center or unit collaborating effectively with the other center(s) or unit(s). The responses below are paraphrased; there are several clusters/themes.

\begin{tabular}{|c|c|}
\hline \multicolumn{2}{|r|}{ Effective Collaboration: STEM Education Centers (SECs) } \\
\hline Theme & Clustered responses \\
\hline None & $\begin{array}{l}\text { - Some STEM centers are now exploring the possibility of } \\
\text { collaborations }\end{array}$ \\
\hline Collaborations & $\begin{array}{l}\text { A number of centers are currently in collaborative, mutually supportive } \\
\text { relationships with other units (such as centers for teaching) related to: } \\
\text { - Campus wide initiatives } \\
\text { - Faculty development programs } \\
\text { - Graduate student development programs } \\
\text { - Collaborating on specific grants }\end{array}$ \\
\hline \multicolumn{2}{|c|}{ Effective Collaboration: Centers for Teaching and Learning (CTLs) } \\
\hline None & $\begin{array}{l}\text { - Some CTLs are now exploring the possibility of collaborating with } \\
\text { STEM Ed centers } \\
\text { - Some are exploring starting a new STEM education-related center }\end{array}$ \\
\hline Collaborations & $\begin{array}{l}\text { A number of CTL directors are currently in collaborative, mutually } \\
\text { supportive relationships with other directors of STEM Ed centers and } \\
\text { related units to share ideas about: } \\
\text { - Cross-institutional committees such as addressing NSF broader } \\
\text { impacts portions of grants and WIDER Steering Committees } \\
\text { - Faculty development programs and internal instructional development } \\
\text { grants } \\
\text { - Postdoctoral fellow development programs } \\
\text { - Collaborating on specific grants (WIDER, REBUILD) }\end{array}$ \\
\hline
\end{tabular}

When we asked centers with both CTLs and SEC on their campus what challenges do you face in working collaboratively with the other center(s) or unit(s), most of answers revolved around lack 
of time (5), balancing collaboration without duplication or competition (3, all by SECs), and different missions of the centers (2). Also mentioned were the challenges in different reporting structures and being seen as an outsider by the science disciplines.

\begin{tabular}{|c|c|}
\hline \multicolumn{2}{|r|}{ Challenges to Collaboration: STEM Education Centers (SECs) } \\
\hline Theme & Clustered responses \\
\hline $\begin{array}{l}\text { Collaboration } \\
\text { with } \\
\text { competition }\end{array}$ & $\begin{array}{l}\text { - All of those listed apply. There is a tension between competing and } \\
\text { collaborating. In general we feel our center has a much broader } \\
\text { mission, with much lower capacity. Having said that our broader } \\
\text { mission helps us distinguish ourselves from CTL and we work } \\
\text { intentionally to avoid overlapping (competing) efforts, there's plenty of } \\
\text { work to do! } \\
\text { - One Center has been on campus much longer, so there are some } \\
\text { historical programs that the new Center is trying to modify. } \\
\text { We have a good relationship. The biggest concern is communicating } \\
\text { with administration so that our independent and complementary } \\
\text { missions and related activities are recognized as equally important and } \\
\text { distinct. }\end{array}$ \\
\hline Time & $\begin{array}{l}\text { - Time is always a factor. It is difficult to add additional components } \\
\text { given the lack of expansion in funding which impacts time. } \\
\text { The biggest barrier is probably time -- all are busy and have full plates. } \\
\text { Carving out time for collaboration is difficult. In addition, while we all } \\
\text { share common goals, we have different backgrounds, assumptions, and } \\
\text { measures of success. }\end{array}$ \\
\hline Staffing & $\begin{array}{l}\text { - The level of staffing at our center is only } 1.75 \text { FTE. [removed] has a } \\
\text { staff of } 35 \text {. [removed] has 13. Complimenting work without } \\
\text { duplicating it. }\end{array}$ \\
\hline $\begin{array}{l}\text { Different } \\
\text { missions }\end{array}$ & $\begin{array}{l}\text { - We do foundational research and not just programming which our } \\
\text { campus considers the purview of CTLs }\end{array}$ \\
\hline $\begin{array}{l}\text { Reporting } \\
\text { structures }\end{array}$ & $\begin{array}{l}\text { - Currently [the SEC] reports to the Dean of CLAS and [the CTL] } \\
\text { reports to a Vice Provost. The distinct reporting structures can } \\
\text { confuse reporting and finances for programs. }\end{array}$ \\
\hline
\end{tabular}




\begin{tabular}{|c|c|}
\hline \multicolumn{2}{|c|}{ Challenges to Collaboration: Centers for Teaching and Learning (CTLs) } \\
\hline Theme & Clustered responses \\
\hline None & $\begin{array}{l}\text { - As of yet, we have not had many obstacles. The collaborative nature of } \\
\text { the two centers is just beginning with the installment of a brand new } \\
\text { director in CUR. } \\
\text { - We do not currently collaborate too much, so we really just need to get } \\
\text { the ball rolling and explore the possibilities. }\end{array}$ \\
\hline Time & $\begin{array}{l}\text { - Just not enough time and resources } \\
\text { - Bandwidth... if we had more time we could do more } \\
\text { - We are so busy that without regularly scheduled meetings our } \\
\text { collaboration falters. We are therefore, increasing collaborative activity } \\
\text { and communication between middle management people through } \\
\text { quarterly luncheons; this is to cross-reference activates, pool resources } \\
\text { and enhance collaboration. We all have the same amount of time; the } \\
\text { issue is what is prioritized. }\end{array}$ \\
\hline $\begin{array}{l}\text { Different } \\
\text { mission }\end{array}$ & $\begin{array}{l}\text { - Not sure yet - but I anticipate there would be some challenges related } \\
\text { to differences in mission, differences in ability to provide incentives for } \\
\text { faculty participation, among other things. }\end{array}$ \\
\hline $\begin{array}{l}\text { STEM } \\
\text { Faculty buy- } \\
\text { in }\end{array}$ & $\begin{array}{l}\text { The project is based on the model used by our campus ADVANCE } \\
\text { program to expose faculty to the research on the impact of unconscious } \\
\text { bias on faculty searches. That process has been quite successful, and it } \\
\text { relies on a group of faculty who learned the research and presented it to } \\
\text { colleagues on campus. [removed] was founded with this model of } \\
\text { faculty talking to faculty, and there has been some reluctance to } \\
\text { involving our center staff in key ways because the model of change is } \\
\text { one of faculty peers only. As a result, we are involved, but we are not as } \\
\text { central to the planning and execution of projects in the individual } \\
\text { STEM departments. }\end{array}$ \\
\hline
\end{tabular}




\section{APPENDIX 3: PROMISING PRACTICES}

Participants were asked about their promising practices in two ways. In the pre-workshop summary, they were asked, "What are the main programmatic activities or practices from your center or unit that you would want others to know about--the "promising practices" in use for STEM educational improvement that you would be willing to share?" During the workshop discussion, they were asked, "What are some of your best practices around engaging faculty? This is not limited to STEM faculty. Has your institution adopted any benchmarks or targets with respect to their goals and vision for the improvement of undergraduate STEM education? What are they? Have you found effective ways of gaining administrator buy-in?”

\section{REFORM PEDAGOGY}

Institutions are reforming pedagogy through faculty development in some of the following ways:

- Convening seminars, symposia, and meetings that focus on Discipline-based education research and/or faculty development around incorporating evidence-based instructional practices in the classroom. Examples include UC Boulder's Discipline-Based Education Research (DBER) Seminar; Purdue University's IMPACT (Instruction Matters: Purdue Academic Course Transformation) and the University of Arizona's Collaborative Learning Spaces.

- Creating faculty learning communities connected to using evidence-based effective practices, faculty mentoring for undergraduate research; course redesign; and course assessment.

- Providing training workshops, orientation for new faculty, and professional development for graduate TAs and post docs (e.g. New Faculty Teaching Excellence Workshop at the University of Notre Dame).

- Hosting special interest groups (e.g. Xavier University's Science Education Research group).

- Teaching a course on college science teaching for postdocs in STEM disciplines. The University of Michigan will host an online version of this course in 2017.

- Hosting summer reading group on faculty development issues and discipline-based education research, taking advantage of faculty in STEM who are on campus doing their research.

\section{VALUING FACULTY}

Institutions are employing innovative practices for valuing faculty who are improving their teaching and scholarship of teaching, and/or who are engaged in research on student learning. Examples include Chancellor awards (University of Colorado Boulder); Innovative teaching fellowships (Saint Louis University); Action research fellowships (Oregon State University); support for site visits with peer and aspirational institutions; and funding for faculty to travel to disciplinary teaching institutes/workshops. 


\section{SCALING}

A few institutions are explicitly focused on understanding and planning for large-scale change across several courses or within/across departments. These can be facilitated by STEM Education Centers that are located in departments or Colleges. As an example, UCLA is using a WIDER grant to seed assessment efforts within and across STEM departments with the goal conducting an audit of teaching practices and using this data to inform the creation of a strategic action plan for adoption of student-centered, evidence-based teaching practices in STEM courses.

Institutions are engaged in activities to scale innovations across the department. A few examples are employing the flipped classroom model (University of Utah); creating course-based undergraduate

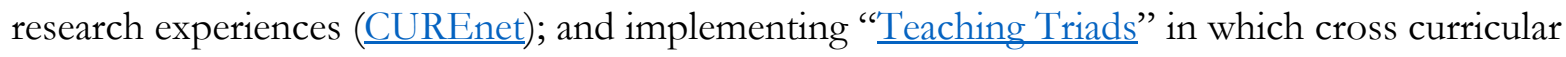
faculty engage in intellectual coaching and the observation of colleagues' teaching with training in different methods of classroom observations (Oregon State University). The University of Maryland is experimenting with a variable credit, self-paced, mastery-based CS course called Paths to Computer Science.

A few projects attempt to scale best practices beyond a single institution. The Integrate STEP Center has 16 institutions that are identifying national challenges in STEM. Project: Transparency in teaching and learning in higher education provides guidance on how faculty can make a student's learning more transparent. STEM Central is a database of resources and network of communities working to transform undergraduate STEM education.

Community engagement and partnering with Pre-K through high school teachers and students is another way in which educational improvements are spread to broader networks.

\section{COLLABORATION (TO SUSTAIN NEW PRACTICES)}

A recurring theme for institutions was the importance of building a community of faculty, staff and community members to support improving STEM education. Several institutions collaborate on faculty development, including faculty advising/mentoring in and out of the classroom. One example is Berea College's collaboration between the Center for Transformative Learning, a faculty member from the Education Department who specializes in STEM teaching and pedagogical research, and two STEM faculty members (physics and chemistry)--all of whom are co-PIs on an NSF WIDER grant. The collaboration allows them to offer ongoing professional development for STEM faculty each year through a week long summer course redesign institute; a year-long professional learning community; classroom observations and interviews of faculty; and training of undergraduate TAs. 
There is also increasing interest in cross-discipline collaborations. Oregon State University has created a new course, Humanitarian Engineering, a collaborative project between the College of Engineering and Outreach and Engagement, which focuses on education, service learning models, and research. The University of Michigan's CRLT Players Theatre Program uses a variety of performance modes and facilitation strategies to support CRLT's mission. Using theatrical representations of a range of issues common in academic life, the performances spark dialogue among faculty, graduate students, and academic administrators, with particular emphasis on issues affecting institutional climate. CRLT Players Theatre has several sketches concerning STEM teaching:

- Climate in the Classroom focuses on chilly climate issues around gender, race, and international status in a physics class; (U of Michigan)

- Conflict in the Classroom focuses on a conversation between students in stats or in medicine that moves quickly from civil dialogue to charged argument (U of Michigan)

\section{INSTITUTIONAL SUPPORT: TOOLS /ANALYSIS INSTITUTIONAL DATA}

Institutions are increasingly using data to make evidence-based decisions. The University of California Davis has tools to map and visualize student data in new ways that help identify actions and priorities. These include pre/post assessment development, classroom observation, tools for visualizing student progress, curricular mapping, and assessment alignment. An example is the Ribbon Tool for student pathways and flows, retention, spread to other disciplines, graduation, and GPA performance. The tool can prompt discussions about goals compared to reality, differences between disciplines, and gaps in performance between groups. UC Davis also has a departmental dashboard with "DFW" (drop, fail, withdraw) rates broken out according to various factors such as when student took the course in their sequence.

Some institutions are tracking swipe card access to campus services to understand how and when students are using writing centers, math centers, and other tutoring opportunities.

The University of Colorado Boulder has "action teams" in departments to address structural issues (e.g., underrepresented populations in a field) with sustainable changes. Oregon State University has created a team of action research fellows who are conducting research on lower level STEM general education courses. 


\section{APPENDIX 4. CENTERS' ROLE IN AND USE OF ASSESSMENT PRACTICES}

During table discussions, Centers were asked:

1) What forms of evidence do you collect to measure the impact of your programs on undergraduate STEM education? (E.g. grant funding, improved retention rates, faculty engagement, data on improved student performance in redesigned courses, etc.).

2) Do you have any assessment methods that have been particularly successful?

Analysis of table discussions is presented below. Data was coded to discern how centers perceived their role in assessment, types of practices currently in use, new practices beginning to be implemented, as well as what tools were used by centers to gather data.

\section{CURRENT PRACTICES AND STRATEGIES}

\section{CENTER'S ROLE}

- Help faculty to design better assessments

- Alignment of learning outcomes with assessments

- Course re-design

- Conduct Needs Assessment:

- Focus groups

- Peer Observations

- Creation of syllabi

\section{SPECIFIC INTERVENTIONS}

- Learning assistants - compare students using learning assistant (LA) program to those not. Include both STEM and nonstem students

- Analysis of teaching artifacts using rubric (before and after intervention)

- Difficult to scale and labor intensive
- Quasi-experimental design looking at student learning indicators in classes of trained vs. untrained faculty.

- Data from course re-design supported by WIDER grant. Measures include:

- Drop/Fail/Withdraw (DFW) rates, gaps for under-rep students

- Interviews with faculty

- Observations of participating faculty 
PROPOSED AND RECENTLY IMPLEMENTED PRACTICES AND STRATEGIES

DATA GATHERING METHODS FOR STUDENT EXPERIENCE

- Follow social media (e.g., yik yak) to look at posts during classes

- Look@DFW rate in courses

- Linguistic analysis of student ownership of learning (beginning)
- Survey students about whether the Center is having an impact on faculty teaching

- Student work and persistence in STEM

DATA GATHERING METHODS FOR FACULTY

- Changes in syllabi and other artifacts after interactions with Center

- Track impact of specific classroom interventions

- Anecdotal feedback from faculty whose evaluations have improved

- Number of grants

- Implementing portfolio process for instructors and faculty - to provide evidence beyond student feedback

- Number of publications

- Count who shows up to workshops and sessions i.e. participation rates

CENTER INTERACTION DATA-BY DISCIPLINE

- Self-report data on:
$\circ$ anticipated impact on future practice
○ consultations

- Meta-analysis across courses to look for themes in mid-semester evaluations
- Follow up surveys and observations (6 months or other) to see if faculty are still using the teaching

- methods they learned - accountability

- Survey faculty beliefs and attitudes about teaching

- Capturing data from LMS (Learning Management System)

TOOLS USED BY CENTERS

- PULSE (biology)

- Department Climate Instrument

- Department Climate indicators

- Department readiness framework (PKAL, Keck)

- Self-determination principles

- COPUS classroom observation protocol

- $\quad \underline{\text { RTOP }}$ observations
- Psychosocial instruments

○ Perceptions of fit

○ Belonging

- Holistic aspects: Have been helpful to faculty (gets away from test performance)

- Student evaluations SETS

- Learning Management System 


\section{APPENDIX 5: POST-WORKSHOP ACTIVITIES}

\section{POST-WORKSHOP SURVEY RESULTS}

There was a 50\% response rate for the post-workshop survey (22 responses). The respondents to the survey characterized their center or unit as a SEC (45\%), CTL (59\%), and/or other (23\%).

$95 \%$ of respondents were satisfied $(36 \%)$ or very satisfied $(59 \%)$ with the workshop. Participants were asked what they liked best about the workshop. Many of them indicated that meeting new colleagues with varied expertise was of value. Participants were also appreciative of how well the workshop was organized. For example:

- I think the workshop was very well organized and the facilitators were very well prepared and well informed (believe it or not, that's rare). I felt like the facilitators hold stake in the outcomes of the workshop, which led to the presence of intentionality and purpose as well as passion. I did not feel like the facilitators, or anyone in the room, had a hidden, personal agenda or were trying to lead participants toward a predetermined answer nor were they trying to tell us what to do. I think this was a great model for experiential and intentional learning that many of us can duplicate within our organizations and/or classes. I appreciated both the time permitted to think and discuss as well as the brevity of several of the sessions. There was a lot of ground to cover and it never felt overwhelming.

- It was productive, intense, and rich. There seems to be momentum and a real possibility to make something happen. Well thought out and executed.

- The opportunity to plug into focused conversations with facilitators/notetakers involved. Opportunity to rotate through different conversations and meet new colleagues. The working memory afforded by a shared Google folder.

In response to how the workshop could be improved, some of the attendees wanted quick fact sheets of each of the centers so that there was better contextual information. Some participants wanted more concrete examples and case studies of effective collaborations. They also wanted more time to process, to network, and to have facilitated discussions with their similar kind of centers. The vast majority of respondents felt that the length of the table discussions (86\%), group discussions (91\%), and lightning rounds (90\%) was just about right. The one activity that some participants said was too short was networking $(32 \%)$.

Participants were asked to what extent they achieved the workshop goals. The vast majority felt that they got to interact with people or programs outside of their usual community. They also felt that they got new ideas that would be useful after the workshop. To some extent, the participants felt that the workshop allowed them to address challenges that they face in improving undergraduate 
STEM education and to identify specific collaborations that may help with their work on STEM education.

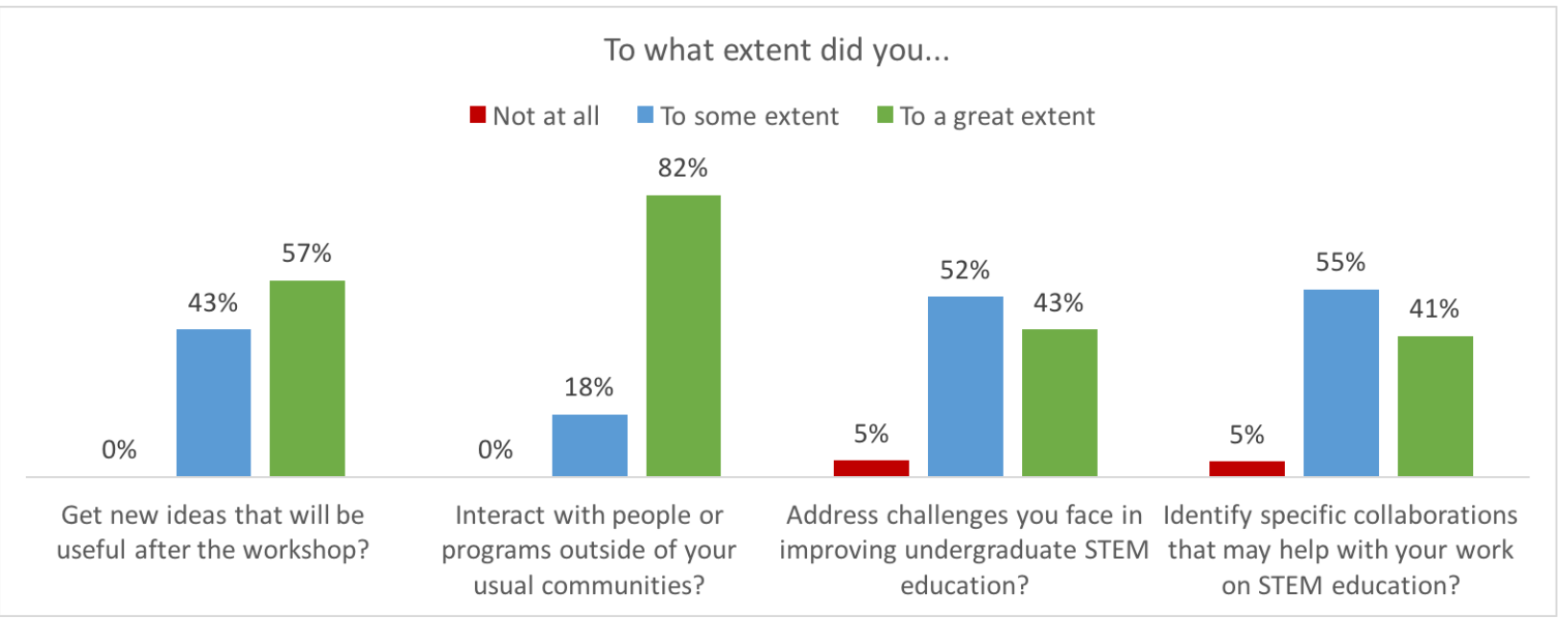

Participants were willing to engage in follow-on activities with the workshop leadership. There was great enthusiasm in participating in a follow-on workshop, but the least interest in helping organize a workshop. There was strong interest in reviewing a draft guide to collaborating at the centers.

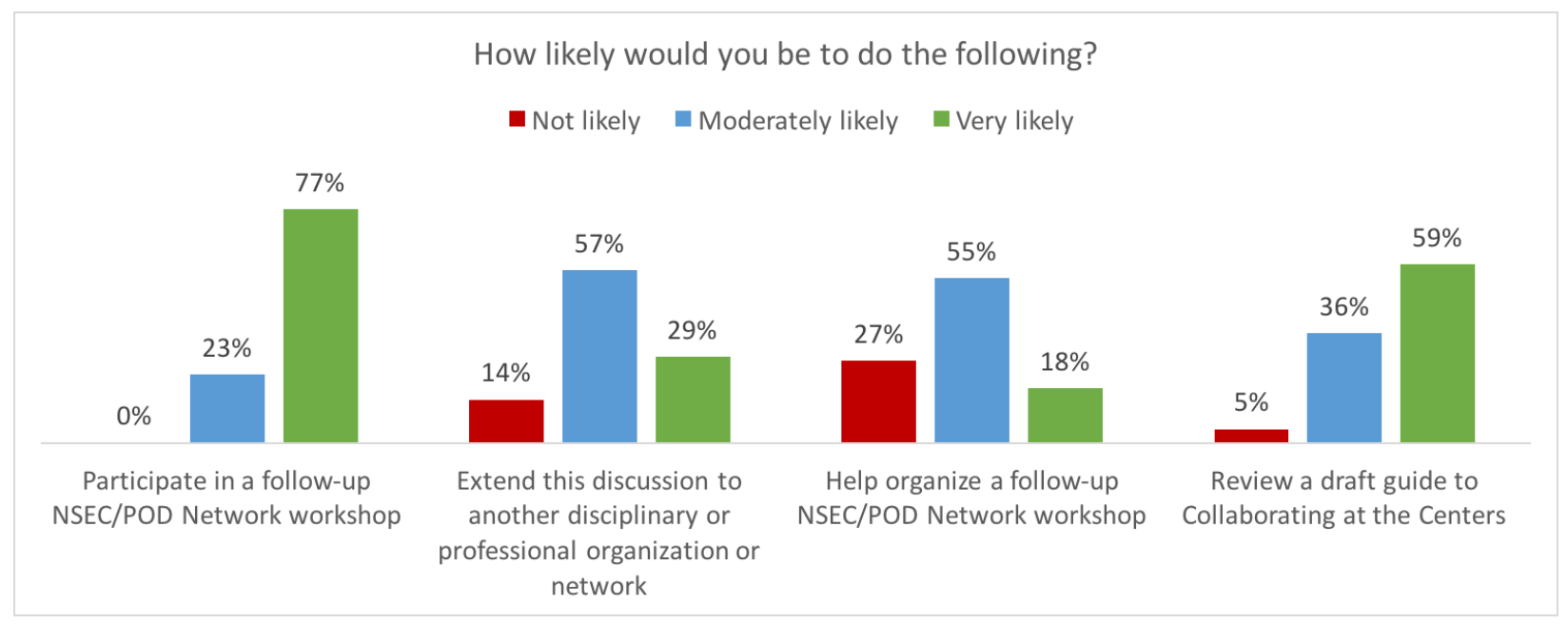

More than half of the attendees said they would work on increasing the collaboration between centers on their campus when they returned home. Others spoke about following up with colleagues they met at the workshop, with a few planning to explore cross-institutional collaborations.

Overall, the workshop design was well received. In the future, similar workshops could be improved by providing more time and analysis to help address the lack of contextual knowledge. 
To date, the following activities are planned.

At the NSEC 2016 National Conference June 8-9, Andrea Beach and Mathew Ouellett will hold a discussion entitled Collaborating at the Centers: CTLs and STEM Centers Continuing Dialogue.

At the NSEC Toolkit Workshop on June 9-10, NSEC is hosting a workshop on building a toolkit for centers. All of the participants from the Collaborating at the Centers Workshop were invited to apply for that invitation-only workshop. All Collaborating at the Centers attendees that applied, were accepted. The eight participants who will attend the Toolkit Workshop are:

1. David Pugalee, University of North Carolina Charlotte - Center Type: SEC

2. Gili Marbach-Ad, University of Maryland - Center Type: SEC

3. Andrew Feig, Wayne State University - Center Type: SEC/CTL Hybrid

4. Tiera Coston, Xavier University of Louisiana - Center Type: CTL

5. Mathew Ouellett, Wayne State University - Center Type: SEC/CTL Hybrid

6. Matt Saderholm, Berea College - Center Type: Academic division; developing a SEC

7. Liesl Baum, Virginia Tech - Center Type: STEM Education Research, Outreach, Advocacy Center

8. Wilella Burgess, Purdue University - Center Type: Interdisciplinary SEC

At the POD Network National Conference on November 11, 2016, Kacy Redd, Cassandra Horii, Mathew Ouellett, Leslie Ortquist-Ahrens, Andrea Beach, Susan Shadle, and Noah Finkelstein will present on Collaborating at the Centers: Transforming STEM and Working Across Boundaries.

The POD Network has established a new, permanent STEM Special Interest Group (SIG), which will receive this report and consult about additional follow-up activities, including the possibility of a special journal issue focused on STEM education reform and the participation of CTLs and SECs, along with other educational and faculty development efforts, future workshops, and other related initiatives.

The POD Network's National Outreach Subcommittee, chaired by Cassandra Horii and Mathew Ouellett with a special charge to focus on STEM since 2014, will share findings and plan next steps with the newly formed External Partnerships and Outreach Committee, to explore building on this work to form deep and enduring partnerships with other organizations.

In addition, this report is being distributed to workshop participants, members of NSEC and the POD Network via listservs and newsletters, and other interested parties. 
We thank the following participants for their contribution to this workshop and workshop report:

Deborah Allen, University of Delaware

Ann Austin, National Science Foundation; Michigan State University

Kevin Barry, University of Notre Dame

Lies1 M. Baum, Virginia Tech

Andrea L. Beach, Western Michigan University

Ben Bederson, University of Maryland

Wilella D. Burgess, Purdue University

Deborah Carlisle, University of Massachusetts Amherst

Steven B. Case, University Of Kansas

Rocio C. Chavela Guerra, American Society for Engineering Education (ASEE)

Sean L. Connin, Trinity University

Joel C. Corbo, University of Colorado Boulder

Tiera S. Coston, Xavier University of Louisiana

Andrew L. Feig, Wayne State University

Noah Finkelstein, University of Colorado Boulder

Richard Freishtat, University of California Berkeley

Alyson L. Froehlich, University of Utah

Emily Gaines, University of Utah

Bruce Goldstein, University of Colorado Boulder

Kumiko Haas, University of California Los Angeles

Charles Henderson, Western Michigan University

Michelle Lee Higgins, University of Arizona

Cassandra Volpe Horii, California Institute of Technology

Eric Hsu, San Francisco State University
Sara Kacin, Wayne State University

Matt Kaplan, University of Michigan

Deandra J. Little, Elon University

Debie Lohe, Saint Louis University

Gili Marbach-Ad, University of Maryland

Emily Miller, Association of American Universities

Susan Magliaro, Virginia Tech

Marco Molinaro, University of California Davis

Cailin Huyck Orr, Carleton College

Leslie Ortquist-Ahrens, Berea College

Mathew L. Ouellett, Wayne State University

Kathryn M. Plank, Otterbein University

David K. Pugalee, University of North Carolina Charlotte

Bryan M. Rebar, University of Oregon

Kacy Redd, Association of Public and Land-grant Universities

Julie Risien, Oregon State University

Matt Saderholm, Berea College

Kay M. Sagmiller, Oregon State University

Erin R. Sanders, University of California Los Angeles

Susan E. Shadle, Boise State University

Rita Teutonico, Florida International University

Gloriana Trujillo, Stanford University

Gabriela Weaver, University of Massachusetts Amherst

Jennifer Weaver, California Institute of Technology

Mary-Ann Winkelmes, University of Nevada, Las Vegas

We thank the National Science Foundation (\#1552540 and \# 1524832) and the Association of Public and Land-grant Universities for their support of this workshop. We thank the POD Network in Higher Education for providing space and support for the workshop.
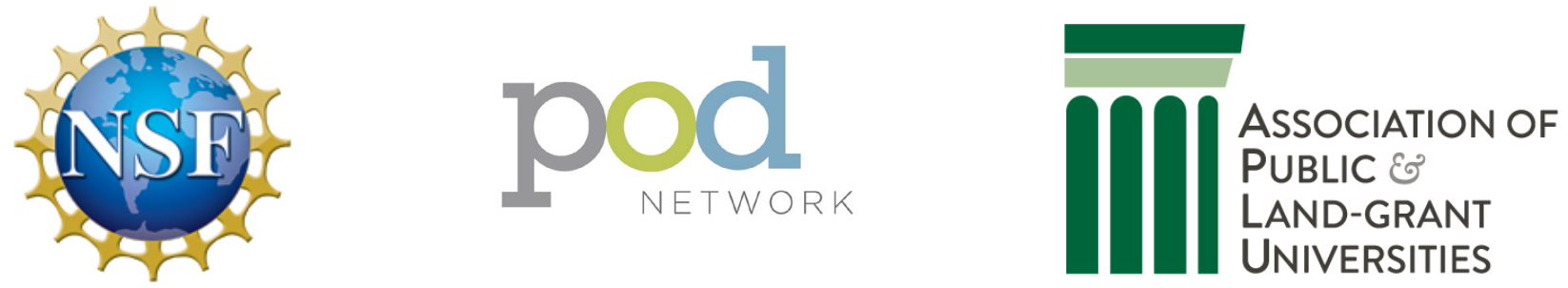